\title{
A Database Creation for Storing Electronic Documents and Research of the Staff
}

\author{
A Case of Department of Educational Communications and Technology
}

\author{
Pornpapatsorn Princhankol \\ Department of Educational Communications and \\ Technology, \\ King Mongkut's University of Technology Thonburi, \\ Bangkok, Thailand
}

\begin{abstract}
The research study aims at creating the database for storing Electronic Documents and Research of the staff in the Department of Educational Communications and Technology, evaluating its quality and measuring the satisfaction of the database by users. The sample subjects are 14 instructors and officers in the Department of Educational Communications and Technology, King Mongkut's University of Technology Thonburi, in the second term of academic year 2012. The research tool is the database for storing Electronic Documents and Research of the staff in Department of Educational Communications and Technology. According to the evaluation by 3 experts in the area of Education Quality Assurance, the values of mean score and standard deviation are 4.51 and 0.38 , respectively. This implies that the corresponding assurance quality of the database is very good. The media quality evaluation by 3 media specialists shows that its mean score is 4.58 and its standard deviation is 0.46 . The evaluation result consequently indicates a very good quality of media. In terms of satisfaction on the database, the results obtained using questionnaires shows high satisfaction scores. The mean score is $\mathbf{4 . 1 5}$ and the standard deviation is 0.55 and this can be concluded that the database can be used effectively in the department.
\end{abstract}

Keywords-database creation; electronic documents; research.

\section{BACKGROUND AND RATIONALE}

Research is an important duty of higher education institutions and universities along with other duties such as teaching, producing graduates and distributing knowledge to the society. Research is important because it builds up knowledge based for instruction and distribution of knowledge, especially in this current society which gains a lot of impact from globalization and advances in technology. Knowledge has played a major role and it could be said that we are now in the era of knowledge management, in other words, instead of managing information, we need to know how to manage various bodies of knowledge. Research is one approach to such knowledge building. Therefore, research is the basis for knowledge management. In higher education institutions, there are many kinds of activities related to knowledge in terms of exploration, maintenance, distribution and application. Research is not only one of the main responsibilities but also has a role in creating and promoting other relevant missions of the universities such as instruction, graduate production and

\author{
Siriwan Phacharakreangchai \\ Department of Educational Communications and \\ Technology, \\ King Mongkut's University of Technology Thonburi, \\ Bangkok, Thailand
}

academic scholarship. Therefore, research is necessary for the economic development and the national innovation. As a result, higher education institutions tend to focus more on research, in terms of both quality and mechanism improvement for research quantity [1].

In 2009, King Mongkut's University of Technology Thonburi was approved by the Office of the Higher Education Commission to be 1 out of 9 Research Universities of Thailand. Therefore, KMUTT continues to do research in order to the meet the standards and to help increase the rankings of Thai universities to be higher in the Times Higher Education QS World University Rankings. Besides research of high quality, the production of high quality graduates is another main responsibility of universities with the aim to create graduates who are both bright and virtuous. KMUTT was funded to improve its potentials in research, innovation and identity [2].

King Mongkut's University of Technology Thonburi always plans to do research and improve the academic excellence through the building up and the application of knowledge in many dimensions. Besides, KMUTT aims at adjusting and renovating the organizations continuously so that the distribution of academic knowledge could be done and integrated with technology and social sciences which are taught on campus.

Faculty of Industrial Education and Technology has a policy to focus on the academic excellence in vocational education, industrial technology and related areas. There are many levels of professional development ranging from undergraduates, Master's and doctoral students. There are also research, training and workshops for the community and this reflects the leadership in vocational education and industrial technology. Moreover, there are links among universities, vocational institutions, organizations, foundations, and professional bodies related to this discipline both from national and international scales.

The policy of the research could be seen as 3 ways: (a) to promote and support research of the staff, students and the personnel in all levels and all disciplines in the Faculty of Industrial Education and Technology; (b) to supervise and oversee the quality of standards, visions, strategies, and mechanism to improve the research works in an efficient 
manner; (c) to promote and distribute the research findings so that there can be a systematic application to reflect the university policy.

Faculty of Industrial Education and Technology always realizes the importance of research and the quality of research output to link or integrate various dimensions of academic excellence, which are research, instruction, technology and professional development. This could lead to the strength in postgraduate educational level. To increase the standards of vocational teachers and technologists is one mission of KMUTT. Hence, there are many research works on the building up of knowledge and innovation for the nation. However, there are no official researchers in the Faculty of Industrial Education and Technology because lecturers and postgraduate students have done research continuously and have published as well as presented their works in both journals and conferences in both Thailand and other countries. There are 3 kinds of research as in engineering research, learning research and general research [3].

In the past, the research works of the staff in the Department of Educational Communications and Technology were stored in the paper format and there were many difficulties. It was inconvenient for searching and retrieval and unresponsive from time to time. Therefore, the researchers would like to create a database for storing electronic documents and research of the staff in the department in order to improve the storage system of the staff.

\section{RESEARCH OBJECTIVE}

1. To create a database for storing electronic documents and research of the staff in the Department of Educational Communications and Technology.

2. To evaluate the quality of the database for storing electronic documents and research of the staff in the Department of Educational Communications and Technology.

3. To measure the satisfaction of the database users about the electronic documents and research of the staff in the Department of Educational Communications and Technology.

\section{EXPECTED OUTCOMES}

1. There would be a database for storing electronic documents and research of the staff in the Department of Educational Communications and Technology.

2. The database for storing electronic documents and research of the staff could be used in the quality assurance process for the Department of Educational Communications and Technology.

\section{RESEARCH SCOPE}

\section{A. Population in This Study}

The population in this study comprised 14 lecturers and administration staff members from the Department of Educational Communications and Technology, King
Mongkut's University of Technology Thonburi in the second term of the academic year 2012.

\section{B. Research Scope}

1. The database would be created for storing electronic documents and research of the staff in the Department of Educational Communications and Technology.

2. The electronic documents and research of the staff in the Department of Educational Communications and Technology would be collected and stored (from 2006 to 2011).

3. There would be links to these electronic documents and research of the staff in the Department of Educational Communications and Technology.

\section{Variables}

The independent variable in this study was the database for storing electronic documents and research of the staff in the Department of Educational Communications and Technology.

The dependent variables in this study were the quality and the satisfaction of the users towards the database for storing electronic documents and research of the staff in the Department of Educational Communications and Technology.

\section{TOOL USED IN THIS RESEARCH}

1. The database for storing electronic documents and research of the staff in the Department of Educational Communications and Technology

2. The quality evaluation form for the database for storing electronic documents and research of the staff in the Department of Educational Communications and Technology

3. The questionnaire on the satisfaction towards the database for storing electronic documents and research of the staff in the Department of Educational Communications and Technology

The statistical approach to this research includes mean, standard deviation and index of congruence (IOC).

\section{RESEARCH RESULTS}

Table I shows the overall quality evaluation by the experts in the area of Education Quality Assurance.

TABLE I. QUALITY EVALUATION

\begin{tabular}{|c|c|c|c|}
\hline Items for Assessment & $\mu$ & $\sigma$ & Quality Level \\
\hline 1 Input & 4.53 & 0.35 & Very Good \\
\hline 2 Process & 4.53 & 0.35 & Very Good \\
\hline 3 Output & 4.47 & 0.46 & Good \\
\hline Mean score & 4.51 & 0.38 & Very Good \\
\hline
\end{tabular}

Table II shows the overall quality evaluation by the experts in the area of Media System. 
TABLE II. QUALITY EVALUATION

\begin{tabular}{|c|c|c|c|}
\hline Items for Assessment & $\mu$ & $\sigma$ & Quality Level \\
\hline 1 Input & 4.53 & 0.46 & Very Good \\
\hline 2 Process & 4.67 & 0.57 & Very Good \\
\hline 3 Output & 4.53 & 0.35 & Very Good \\
\hline Mean score & 4.51 & 0.38 & Very Good \\
\hline
\end{tabular}

Table III shows the overall satisfaction of the users towards the database for storing electronic documents and research of the staff in the Department of Educational Communications and Technology.

TABLE III. USER SATISFACTION

\begin{tabular}{|c|c|c|c|}
\hline Items for Assessment & $\mu$ & $\sigma$ & $\begin{array}{c}\text { Satisfaction } \\
\text { Level }\end{array}$ \\
\hline 1 Input & 4.59 & 0.55 & The Highest \\
\hline 2 Process & 4.46 & 0.54 & High \\
\hline 3 Output & 4.49 & 0.57 & High \\
\hline Mean score & 4.51 & 0.55 & The Highest \\
\hline
\end{tabular}

\section{RESEARCH RESULT SUMMARY}

\section{A. Result from the Creation of Database}

According to the result from the creation of database for storing electronic documents and research of the staff in the Department of Educational Communications and Technology, this research met the expectations as it was developed and revised according to the suggestions and advice given by the experts. The data were analyzed and this database was already installed in the Department of Educational Communications and Technology.

\section{B. Resulst from the Quality Evaluation of the Database by the Experts in Education Quality Assurance}

The results from the quality evaluation of the database by the experts in the area of Education Quality Assurance showed that the input was 4.53 on average with standard deviation of 0.35 or at very good level. As for the process, the mean score was 4.53 with standard deviation of 0.35 , or at very good level. As for the output, the mean score was 4.47 with standard deviation of 0.46 or at good level. Therefore, the overall quality as assessed by the experts was 4.51 with standard deviation of 0.38 . It means that the quality in terms of education quality assurance was at very good level.

\section{Results from the Quality Evaluation of the Database by the Experts in Educational Media}

The results from the quality evaluation of the database by the experts in educational media showed that the mean score for input was 4.53 with standard deviation of 0.46 or at very good level. As for the process, it was 4.67 on average with standard deviation of 0.57 , or at very good level. In terms of output, the mean score was 4.53 with standard deviation of 0.35 , or at very good level. Therefore, the overall mean score by the experts in educational media was 4.58 with standard deviation of 0.46 . This means that the quality in terms of educational media was at very good level.

\section{Results from the Users' Satisfaction towards the Database}

The results from the users' satisfaction towards the database for storing electronic documents and research of the staff in the Department of Educational Communications and Technology showed that the mean score for input was 4.59 with standard deviation of 0.55 , or at the highest level. As for the process, the mean score was 4.46 with standard deviation of 0.54 , or at high level. In terms of output, the mean score was 4.49 with standard deviation of 0.57 , or at high level. Therefore, the overall mean score for the users' satisfaction was 4.51 with standard deviation of 0.55 . This means that the users expressed the highest satisfaction level.

\section{RESEARCH DISCUSSIONS}

\section{A. Quality Evaluation of the Database}

The results from the quality evaluation of the database for storing electronic documents and research of the staff in the Department of Educational Communications and Technology showed that the quality in terms of quality assurance was at very good level and that the quality in terms of educational media was also at very good level. This means that the database was effective and suitable for storing electronic documents and research of the staff so that the documents could be used for quality assurance and for those who would like to find research works related to their work. Since the research documents could be dated back 5 years ago (2006-2010), a systematic approach will facilitate document storage and retrieval. This means that it could be searched in a short time and there will be more physical space for other documents. This view complies with the research work by Khonsan Reetanont [3] in that the existing educational quality assurance system in the Department of Educational Communications and Technology still depends on paper and it results in a large amount of paper. It takes longer time to find a document and it is inconvenient. Moreover, certain information might be lost or damaged and it could not be retrieved. The quality assurance results might not be satisfactory. Therefore, the new database system can provide the following features:

1. The electronic documents and research of the staff would be stored in a systematic order so that it is more convenient and quicker to retrieve the file.

2. There would be a decrease in physical space for storing the data. Moreover, it could prevent data loss or damaged documents.

3. The staff member could edit, modify and keep the data up to date to meet the demands of the users.

\section{B. Users' Satisfaction towards the Database}

As for the users' satisfaction towards the database for storing electronic documents and research of the staff in the Department of Educational Communications and Technology, it was found that the users expressed the highest level for the input because it was convenient and quick to put the data into the database. It was also quick to edit, modify, check and verify 
the data. Moreover, there are useful features such as automatic input and keywords so that the users can gain access to the database in a short time (as this point is the most satisfactory for users). To be able to gain access quickly means that the data could be kept up-to-date and that it could be used at anytime.

As for the process, the users expressed high level of satisfaction, especially towards the system procedure because it was easy to follow and there was no confusion. The system was table without error, resulting in less time for operation. There was also a system for feedback and comment from users so that the system could be modified to meet the demands of users. This view was similar to Jidapas Samphansomphot and Chaiyong Uprasitwong [4] in that the use of electronic document storage system could benefit to the uttermost and this would motivate the staff members to make the best use of the system. However, the compatibility must be taken into account for each department because the data could be changed all the time and each change in the system must improve the effectiveness of the data storage system.

As for the output, it was found that the users' satisfaction was at high level because the data display was quick, accurate and comprehensible. The data met the demands of the users and they were presented in an attractive manner with graphics, colors and illustrations. Moreover, the format and the text as well as the layout help embellish the display. According to the questionnaire results, it was found that the population expressed a high level of satisfaction because this database could reduce the operation time and the data were displayed in a comprehensible manner. The system was designed to store many kinds of information, including the data in the format of hard copy and digital file. It was also designed to reflect the actual structure of the filing system so that it is easy to gain access in the future. This operation was in compliance with the research by Orathai Thammasiri [5] in that the electronic document storage system is an extended version of the electronic catalogue system which involves the document operation. At the present time, there is an increase in the users, both centrally and locally. This could help solve many problems and it results in more convenience and data exchange.

\section{SUGGESTIONS}

\section{A. Suggestions for the Application of Research Results}

According to the research results, it could be found that the creation of the database for storing electronic documents and research of the staff in the Department of Educational Communications and Technology was suitable and could be a model for other departments or organizations to build a database for storing their own data. The essential information for those who are interested in building up a database could be as follows:

1. Data preparation must be done through a systematic classification. Then the documents could be converted into PDF format and the title must be named in accordance with the topic so that it is convenient to find the file when it is uploaded.

2. Database design must be based on the analysis of data storage preference. The table must be designed after an analysis of the way the users store their data so that it is convenient to gain access to the file. The interface must be designed to interact with the users. The main focus should be on convenience for each component.

3. Virtual server installation could be done using AppServ software (Version 2.54a for Windows or higher) in order to simulate how the database would be used in the real situation. Since AppServ software contains compiler for PHP, MySQL and Server system, the operation could reflect the actual usage on the real server.

4. Centre for functionality could be made so that it is more convenient to use and edit commands when there is an error message. Moreover, it could reduce the delay when the system is used simultaneously.

According to the research results, the input, the process and the output are the main components for the database. Therefore, for those who would like to create a database, the procedure and the relationship among these three components must be taken into account for that the system could achieve its quality.

\section{B. Suggestions for Further Research}

1. There can be research on the creation of database for storing electronic documents and research of the Faculty of Industrial Education and Technology, King Mongkut's University of Technology Thonburi.

2. There can be a study on the creation of database regarding the training seminars of the lecturers and staff in the Faculty of Industrial Education and Technology, King Mongkut's University of Technology Thonburi.

\section{REFERENCES}

[1] S. Khowilaikul, "Strategies to Develop Research Culture in Higher Education Institutions," Journal of Education (Local), Chulalongkorn University, vol. 29, no. 1 (July-October 2000), 2000, pp. 8-18.

[2] King Mongkut's University of Technology Thonburi, Annual Report 2009, Bangkok: Amarin Printing PLC, 2009, p. 5

[3] K. Reetanont, "The Development of Information Technology System for Educational Quality Assurance: A Case Study of the Department of Computer and Educational Technology," a Master's thesis in Computer and Information Technology, Faculty of Industrial Education and Technology, King Mongkut's University of Technology Thonburi, 2006, p. 69.

[4] J. Samphansomphot, and C. Uprasitwong, "Information System for Management", [Online], http://courseware.payap.ac.th/docu/sc312/lesson5/lesson05.htm [Retrived: 20 March, 2010].

[5] O. Thammasiri, "Electronic Document Storage", [Online], Available: http://kmcenter.rid.go.th/kmc13/d_b/judgeb.htm [Retrieved: 14 February, 2011].

\section{AUTHORS PROFILE}

Associate Professor Dr. Pornpapatsorn Princhankol is Assistant Dean in Educational Quality Assurance, Faculty of Indutrial Education and Technology, King Mongkut's University of Technology Thonburi

Siriwan Phachrakreangchai is a graduate student of Department of Eduational Communications and Technology, Faculty of Indutrial Education and Technology, King Mongkut's University of Technology Thonburi, Thailand

\section{APPENDIX}

Screenshots of the database for storing electronic documents and research of the staff in the Department of Educational Communications and Technology: 


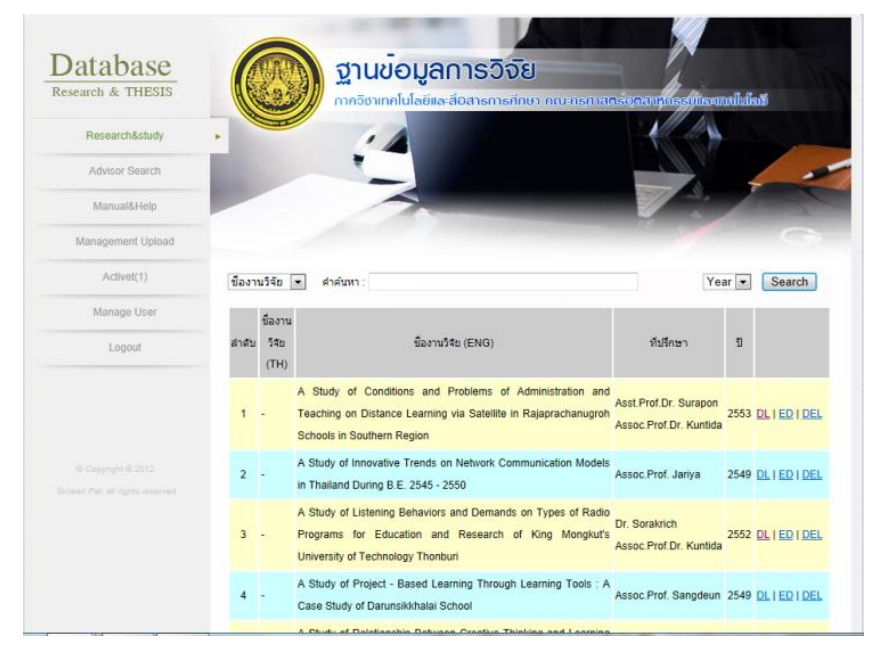

Figure 1. Screenshot of database main page

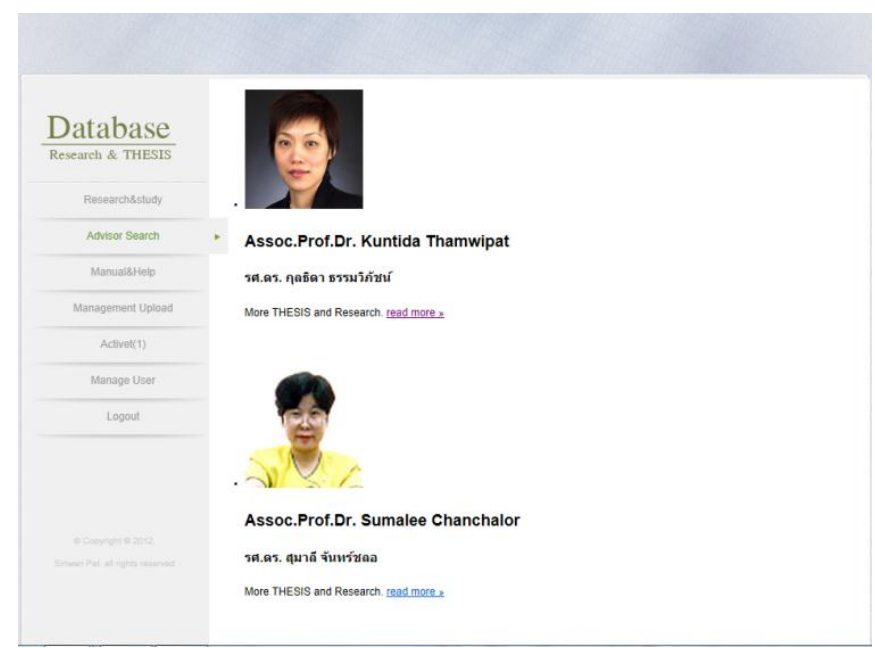

Figure 2. Screenshot of database access through advisor search

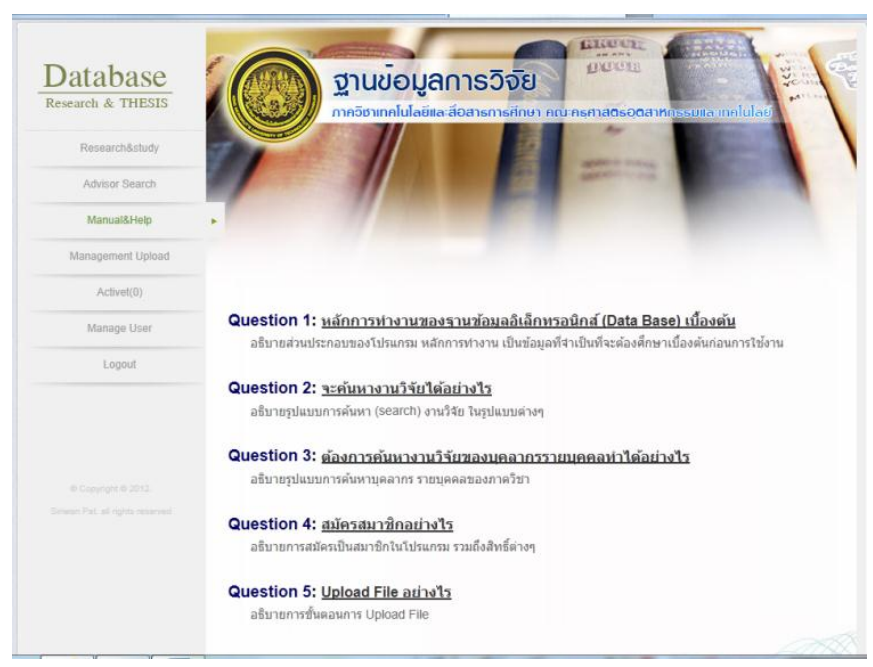

Figure 3. Screenshot of database access through manual and help

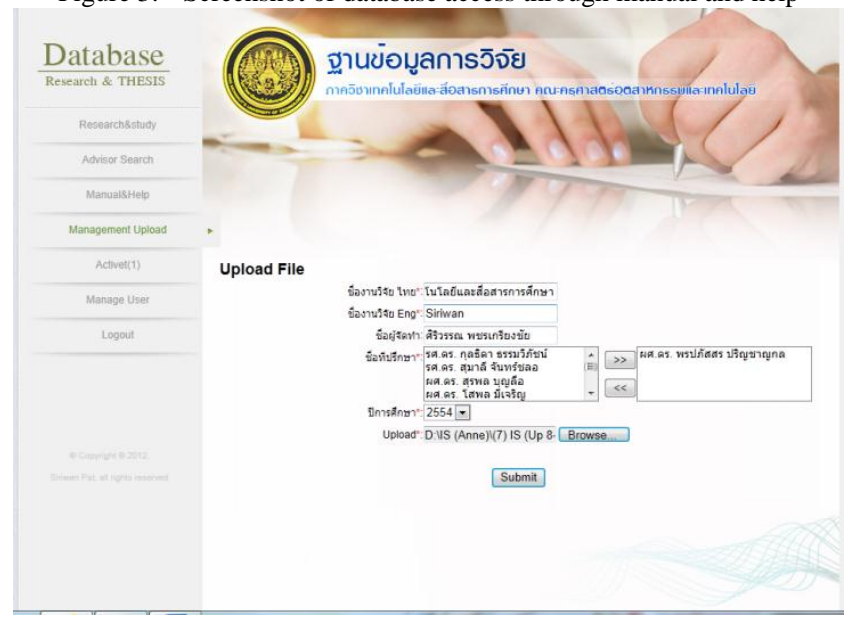

Figure 4. Screenshot of upload page to store documents in the database 